\title{
Nonsectarian Welfare Statements
}

\section{Citation}

Cass R. Sunstein, Nonsectarian Welfare Statements (Olin Center Faculty Discussion Papers No. 773, 2014).

\section{Published Version}

http://www.law.harvard.edu/programs/olin_center/papers/773_Sunstein.php

\section{Permanent link}

http://nrs.harvard.edu/urn-3:HUL.InstRepos:13030949

\section{Terms of Use}

This article was downloaded from Harvard University's DASH repository, and is made available under the terms and conditions applicable to Open Access Policy Articles, as set forth at http:// nrs.harvard.edu/urn-3:HUL.InstRepos:dash.current.terms-of-use\#OAP

\section{Share Your Story}

The Harvard community has made this article openly available.

Please share how this access benefits you. Submit a story.

\section{Accessibility}




\title{
HARVARD
}

JOHN M. OLIN CENTER FOR LAW, ECONOMICS, AND BUSINESS

\author{
NONSECTARIAN WELFARE STATEMENTS \\ Cass R. Sunstein \\ Forthcoming in Regulation \& Governance
}

Discussion Paper No. 773

$06 / 2014$

Harvard Law School

Cambridge, MA 02138

This paper can be downloaded without charge from:

The Harvard John M. Olin Discussion Paper Series: http://www.law.harvard.edu/programs/olin_center/

The Social Science Research Network Electronic Paper Collection:

http://ssrn.com 
Preliminary draft 8/28/2013

For Regulation \& Governance

Symposium on Institutional Dysfunction

\title{
Nonsectarian Welfare Statements
}

\author{
Cass R. Sunstein*
}

\begin{abstract}
How can we measure whether national institutions in general, and regulatory institutions in particular, are dysfunctional? A central question is whether they are helping a nation's citizens to live good lives. A full answer to that question would require a great deal of philosophical work, but it should be possible to achieve an incompletely theorized agreement on a kind of nonsectarian welfarism, emphasizing the importance of five variables: subjective well-being, longevity, health, educational attainment, and per capita income. In principle, it would be valuable to identify the effects of new initiatives (including regulations) on all of these variables. In practice, it is not feasible to do so; assessments of subjective well-being present particular challenges. In their ideal form, Regulatory Impact Statements should be seen as Nonsectarian Welfare Statements, seeking to identify the consequences of regulatory initiatives for various components of welfare. So understood, they provide reasonable measures of regulatory success or failure, and hence a plausible test of dysfunction. There is a pressing need for improved evaluations, including both randomized controlled trials and ex post assessments.
\end{abstract}

"The world of costs and benefits (which includes taking note of the badness of nasty actions and of violations of freedom and rights) is quite a different decisional universe from the sledgehammer reasoning of consequence-independent duties and obligations."

-Amartya Sen ${ }^{1}$

\section{Nonsectarian Welfarism}

In the world of administrative law, and sometimes more generally, there is periodic talk of some kind of "dysfunction" or "crisis," perhaps in the form of a "crisis of legitimacy." Talk of dysfunction or crisis can have various sources. It might stem from real or apparent public disaffection -- perhaps shown by opinion polls

* Robert Walmsley University Professor, Harvard University. 
that reveal high levels of trust or low levels of faith in government performance. Alternatively, talk of dysfunction might stem from a widespread sense, on the part of media elites and influential political leaders, that the system is in some respect "broken." Well-publicized trends, events, or incidents might suggest that something is badly wrong; consider a serious economic downturn, persistent economic stagnation, high levels of poverty, or an environmental disaster. A nation might suffer from "gridlock," reflected in a situation in which apparently desirable reform legislation cannot pass. Implementation of important legislation might prove difficult. Citizens might be discouraged by persistent political polarization. They might have a sense that the political system is incapable to responding to some recurring problem (such as poverty or climate change).

With respect to institutions in general, my principal suggestion here is simple: claims of dyfunction or crisis should stand or fall largely on the basis of a single criterion, which is whether people in the relevant society are able to live good lives. ${ }^{2}$ This criterion, meant to be welfarist, suggests that whether regulatory institutions are dysfunctional depends on whether they are promoting, or undermining, the goal of allowing or helping citizens to be able to live good lives. An authoritarian government is highly likely to be dysfunctional in this sense. A government that regulates too much may also be dysfunctional; the same is true of one that regulates too little; the same is true of a government that chooses the wrong regulatory tools. Hayekians can certainly be welfarists. The same is true of New Dealers and social democrats.

It should be clear that the criterion needs to be specified, and that in the abstract, it is compatible with a diverse array of ideals and commitments. But notice immediately what it rules out. If a political system is badly polarized, or if there is "gridlock," nothing need be badly amiss. Certainly there is no crisis if people in that society are free, healthy, happy (in the relevant sense), and prosperous. This is so even if public opinion polls suggest a widespread absence of confidence in the society's political institutions (though an absence of confidence would require independent explanation). If legislatures are issuing few laws and if agencies are issuing few regulations, there need be no dysfunction, even if members of the public, or segments of the public, seek many more regulations. And if there is a flurry of legislative or regulatory activity, perhaps suggestive of some kind of chaos, we may not have dysfunction unless there is a problem in terms of people's welfare.

\section{The Central Issues}

A sustained effort to specify the welfarist view would take us into highly contested philosophical territory. ${ }^{3}$ For present purposes, let us attempt to bracket

2 I am bracketing the question of obligations to future generations.

3 For valuable discussion, see Matthew Adler, Well-Being and Fair Distribution (2011); Amartya Sen, Development As Freedom (1990). 
the hardest questions and seek an incompletely theorized agreement ${ }^{4}$ on what that view entails - that is, an agreement that can be joined by people with disparate philosophical commitments, and by people who are unsure what their commitments are. I suggest that it is possible to obtain an incompletely theorized agreement on behalf of nonsectarian welfarism - a form of welfarism that abstracts from a wide range of theoretical debates, and that can be accepted by people who would specify welfarism is many different ways. ${ }^{5}$

Of course it is true that no form of welfarism can be entirely nonsectarian. Some people are not welfarists; they believe that rights are what count, and that people's rights do not depend on any kind of welfarist calculation. Moreover, people can specify the idea of welfare in incompatible ways. Perhaps the best life is one that involves fidelity to God's will, understood in a certain way. Perhaps the best life is one that involves a certain kind of labor. Insofar as it does not endorse such views, the very idea of nonsectarian welfarism is a bit of a cheat. Nonetheless, I suggest that it is possible to bracket at least many of the philosophical debates, and to proceed in a way that that is acceptable to diverse people, by focusing on five variables: subjective well-being (SWB); longevity; health; educational attainment; and wealth. ${ }^{6}$ To be sure, other variables are candidates; consider, for example, a decent environment, or clean air and water. But the strongest candidates are closely related to the five that I have identified, and if a nation does well along those five dimensions, it is highly likely to be doing well along others.

\section{A. SWB}

On the view I am suggesting, SWB is exceedingly important: Are people enjoying their lives, or are they miserable? The answer is central to any assessment of institutional dysfunction. To be sure, efforts to provide that answer present serious empirical challenges. A growing literature on "happiness" attempts to meet those challenges. ${ }^{7}$ We have learned, and are continuing to learn, a great deal. We know, for example, that there is a positive relationship between life satisfaction and income ${ }^{8}$ and that unemployment has extremely serious adverse affects on SWB. ${ }^{9}$ Of

\footnotetext{
${ }^{4}$ See Cass R. Sunstein, Incompletely Theorized Agreement, 108 Harv L Rev 1733 (1995).

${ }^{5}$ An instructive discussion of welfarism can be found in Matthew Adler, Well-Being and Fair Distribution (2011). Note that I am focusing here on outcomes, not on processes, and hence not on whether and to what extent people are self-governing. The democratic ideal of course deserves independent attention (as does the idea of freedom). If people are doing well in relevant respects, but not in charge of their own political fates or their own lives, something is badly amiss. Note in addition that democratic safeguards and well-being are causally related. See Amartya Sen, Development As Freedom (1990).

${ }^{6}$ Note that the annual UN Human Development Report focuses on three of these factors: per capita income, longevity, and educational attainment.

7 See Alan Krueger et al., Measuring the Subjective Well-Being of Nations (2009).

${ }^{8}$ Betsey Stephenson and Justin Wolfers, Economic Growth and Subjective Well-Being:

Reassessing the Easterlin Paradox (2008), available at

http://www.nber.org/papers/w14282
} 
course it is true that institutions cannot magically inflate SWB. But to the extent that institutions help to increase SWB (as, for example, by increasing employment), they would appear to be functioning well. If they depress SWB (as, for example, by decreasing employment), they would appear to be functioning badly. Efforts to reduce the incidence and effects of mental illness (which has especially harmful effects on SWB) deserve high priority; so too with efforts to reduce the incidence and effects of pain.

It is reasonable to ask how SWB is measured. In most of the relevant research, people use a scale of, say, 0 to 8 to answer questions about how happy they are or how satisfied they are with their lives. Skeptics might ask: Do answers to such questions tell us anything at all? As a matter of fact, people's answers do turn out to be associated with independent tests of people's hedonic state, including frequent smiling, smiling with the eyes, quality of sleep, happiness ratings by friends, self-reported health, frequent expressions of positive emotions, and being sociable and outgoing. ${ }^{10}$ To date, no empirical work has falsified or even seriously undermined the suggestion that reports of global happiness reflect actual happiness, understood as subjective mental states.

Skeptics might persist at this point, suggesting that what matters is not what people say about their global life satisfaction but, instead, how people are actually feeling from day to day or from moment to moment. And in fact, efforts have been made to assess people's subjective well-being in this way. ${ }^{11}$ We should not be surprised to find that in some domains, answers to global questions will be different from what emerges from aggregations of moments. ${ }^{12}$ Asked about how their life is going, divorced or unmarried people might give relatively less positive answers, focusing on the fact that they are unmarried; but perhaps unmarried people experience more, and not less, moment-by-moment happiness.

There are difficult questions about the proper measure. Perhaps what matters most is moment-by-moment happiness, insofar as that measure captures people's actual experience. Perhaps life satisfaction reflects people's off-the-cuff responses to survey questions, and does not say much about how they are experiencing their lives. But it is imaginable that life satisfaction helps to capture aspects of experience that moment-by-moment measures do not, such as whether people believe their lives to be meaningful or well-lived. People might enjoy their

\footnotetext{
${ }_{9}^{9}$ See Richard E. Lucas et al., Unemployment Alters the Set Point for Life Satisfac- tion, 15 Psychol. Sci. 8, 11 (2004) ("People were less satisfied in the years following unemployment than they were before unemployment, and this decline occurred even though individuals eventually regained employment.").

${ }^{10}$ Daniel Kahneman and Alan Krueger, "Developments in the Measurement of Subjective WellBeing," Journal of Economic Perspectives 20, no. 1 (Winter 2006): 3-24.

${ }^{11}$ Daniel Kahneman et al., "A Survey Method for Characterizing Daily Life Experience: The Day Reconstruction Method," Science 306, no. 5702 (December 3, 2004): 1776-80. 12 Id.
} 
moments without believing, on reflection, that they have the lives they want. There is a good argument that both measures matter. At the very least, we can say that if a population, or significant subsegments, do not like their lives, or are not satisfied with them, something is badly amiss.

\section{B. Longevity and Health}

From the standpoint of nonsectarian welfarism, there is a serious problem if people's lives are relatively short, even if SWB is high. Longevity is independently important. A society with a life expectancy of 60 is doing less well than a society with a life expectancy of 80. In exploring the issue of institutional dysfunction, it is necessary to engage this issue as well.

Health is of independent interest. Of course longevity and health are correlated, and in principle, there should be a strong correlation between subjective well-being and health. People who are sick are unlikely to enjoy their lives. But the relevant values are independent. We could imagine a society with very high levels of well-being but without high (enough) levels of good health. Perhaps those without good health have adapted to their situation, so that their hedonic states are pretty good, ${ }^{13}$ even though their health greatly limits what they can do and be. ${ }^{14}$ If so, the society is not sufficiently promoting people's welfare in the sense in which we should understand the term. A society facing widespread health problems is dysfunctional. ${ }^{15}$

\section{Education and Income}

Educational attainment is also a central part of welfare, properly understood. Here too there is a correlation among relevant factors. A society that shows high levels of subjective well-being, longevity, and health is likely to be providing good education, which is at least correlated with longevity and health. But good education has independent importance. Those who are more fully educated are able to have fuller and better lives.

What about wealth, as reflected, for example, in per capita GDP? The central point is that wealth is an all-purpose means; it helps people to obtain a wide assortment of goods. ${ }^{16}$ GDP growth appears to be associated with subjective wellbeing, ${ }^{17}$ and to that extent, such growth is instrumentally important. Some early work suggested that after a certain point, GDP growth does not improve subjective

\footnotetext{
13 See the discussion of adaptive preferences in Jon Elster, Sour Grapes (1983).

${ }^{14}$ See the discussion of capabilities in Amartya Sen, Development As Freedom (1990).

${ }^{15}$ See Martha Nussbaum, Creating Capabilities: The Human Development Approach (2011).

16 See John Rawls, A Theory of Justice (1970).

17 See Stevenson and Wolfers, supra note.
} 
well-being, but the most recent research strongly suggests otherwise. ${ }^{18}$ Even if the association were less clear, higher per capita income allows people to enjoy objectively better lives, whether or not their subjective well-being remains constant. If people have more wealth, they are able to be and to do more. For this reason, it makes sense to consider per capita GDP as an admittedly imperfect measure of social welfare.

\section{Distributional Considerations}

There are also distributional questions. If a society has a high per capita GDP, and if its average citizen is doing well in terms of SWB, longevity, health, and educational attainment, there is nonetheless a serious problem if some fragment of the society is doing terribly along one or another of these dimensions. ${ }^{19}$ Severe distress for some such fragment should generally be seen to suggest a kind of institutional dysfunction, one that may indicate the need for significant reform. Consider the idea of prioritarianism, insisting that public officials should give special priority to those who are least well-off. ${ }^{20}$ Prioritarianism is a sectarian form of welfarism, because many people do not accept it, but we should be able to agree that if a number of people are miserable or poor, or have poor health and short lives, institutions are not working well. The relationship between aggregate welfare and distribution is of course highly contested, but nonsectarian welfarism requires at least a degree of attention to questions of distribution.

\section{Regulatory Function and Dysfunction}

What is the relationship between regulation and nonsectarian welfarism? Can regulatory institutions help to increase subjective well-being? If they are functioning well, will they increase longevity and improve health? Should we ask agencies to accompany significant rules with SWB Impact Statements, Longevity Impact Statements, and Health Impact Statements? Should we require some kind of annual accounting? Should agencies have to explore the effects of their decisions on human capabilities and functionings ${ }^{21}$ ?

\section{A. In Principle}

It should be emphasized that institutions in general, and specific regulatory institutions in particular, are likely to have limited control over the relevant variables. In any particular nation, it may not be so easy to produce a material

18 See Betsey Stephenson and Justin Wolfers, Subjective Well-Being and Income: Is There Any Evidence of Satiation?, 103 Am Econ Rev: Papers and Proceedings 598 (2013).

${ }^{19}$ For a vivid discussion, see Jean Dreze and Amartya Sen, An Uncertain Glory: India and its Contradictions (2013).

20 See id.

21 See Amartya Sen, Commodities and Capabilities (1985); Martha Nussbaum, Creating Capabilities: The Human Development Approach (2011). 
increase in SWB, certainly not in the short run, and most agencies will not be in a position to increase longevity. For all of the relevant variables, agencies may have, at best, a limited "band" in which to do their work. Some agencies will not have any kind of control over any of those variables.

At the same time, it is true that if agencies had access to the relevant information, and if they could costlessly obtain it, they should disclose and consider it in deciding whether and how to proceed. If, for example, an agency knows that its decision would significantly affect SWB, it should say so. ${ }^{22}$ And indeed, there is an argument that SWB analysis has significant advantages over conventional approaches (such as cost-benefit analysis), insofar as it captures directly an important variable that such approaches can at best approach indirectly. ${ }^{23}$ To say this is not at all to say that SWB is all that agencies should consider. But in principle, it is an exceedingly important factor.

\section{B. In Practice: Of Action and Inaction}

With respect to SWB, the administrative challenges are particularly formidable. If an agency is limiting the hours of service for truckers, or if it is restricting emissions of particulate matter, it may not be feasible to measure the effects on SWB. But agencies should nonetheless be possible to make progress on some critical variables. In such cases, it may well be possible to identify mortality and morbidity effects, and to do so as part of a formal Regulatory Impact Analysis (RIA). In the United States, agencies routinely produce RIAs for economically significant rules (those that cost more than $\$ 100$ million per year ${ }^{24}$ ), and those statements do attend to mortality and morbidity.

In their ideal form, RIAs are essentially Nonsectarian Welfare Statements. They provide a serviceable measure of the effects of regulatory actions on social welfare. To the extent that they are grounded in actual evidence, and essentially accurate, they provide a good measure of whether regulatory institutions are functional or not. If the result of regulatory action is to save significant numbers of lives, and to prevent large numbers of illnesses or accidents, there is a strong argument for going forward, at least if the action does not have substantial adverse effects of welfare. Institutions that fail to act, in such circumstances, are dysfunctional. And if a regulatory action would have only modest beneficial effects but cost a great deal, and if those costs are reasonably translated into adverse effects on welfare, then functional institutions do not proceed.

22 John Bronsteen et al., Well-Being Analysis vs. Cost-Benefit Analysis, 62 Duke LJ 1603 (2013).

23 See Note, Happiness Metrics in Federal Rulemaking, 27 Yale J Reg 115 (2010).

24 This is an oversimplification. See Cass R. Sunstein, The Office of Information and Regulatory Affairs: Myths and Realities, 126 Harv L Rev 1838 (2013) for a more detailed account. 
In some circles, of course, RIAs are seen as cost-benefit analyses, pure and simple, and cost-benefit analysis (CBA) is highly controversial, not least because of the effort to turn various consequences (including the risk of premature death) into monetary equivalents. ${ }^{25}$ In producing RIAs, of course, agencies do not "value life" or assign monetary values to lives as such. Instead they are concerned with statistical mortality risk. If they find, for example, that people are willing to pay $\$ 90$, and no more, to eliminate a risk of 1 in 100,000, they might value a life at $\$ 9$ million, which really means that statistical risks of 1 in 100,000 are valued at $\$ 90.26$ For questions of this kind, part of the argument for monetization is that in its absence, it is not simple to trade off relevant variables, and the effort to use a common metric can make transparent what would otherwise be obscure and undisclosed. Suppose, for example, that a highway safety rule would prevent sixty premature deaths every year, and that it would cost $\$ 600$ million. If the agency knows these facts and decides to proceed, it is saying that a human life is worth at least \$10 million. Might it not be best if an agency assigns some kind of explicit monetary value to the benefits with which it is concerned, rather than making tradeoffs implicitly?

If RIAs are seen as efforts to reflect a kind of nonsectarian welfarism, it should be clear that the "bottom line" figures, reflecting total costs and benefits, do not capture everything that is at stake. Those figures are only a proxy for what matters. But the proxy is not a bad one, and RIAs include not merely the proxy, but also a wide range of qualitative details about anticipated effects on morbidity, mortality, and other variables. Insofar as a rule is designed to improve educational outcomes, the accompanying RIA will describe the anticipated improvements as well.

It follows that in deciding whether regulatory institutions in general are functioning well, it makes sense to give careful consideration to the aggregate assessment that is provided by the full universe of relevant RIAs. And in fact, the United States government offers such an assessment, capturing annual and ten-year effects, at least in terms of benefits and costs. ${ }^{27}$ The net benefits, in any given year, provide at least a plausible indicator of the performance of regulatory institutions.

Unfortunately, that number does not provide information about unjustified inaction - about regulations that would have had significant net benefits but that never saw the light of day. It is a potentially serious form of dysfunction not to issue such regulations; the failure to do so will compromise all of the variables that constitute nonsectarian welfarism. For example, unjustified inaction might create

25 See Lisa Heinzerling and Frank Ackerman, Priceless (2008).

26 See W. KiP VisCuSI, Rational Risk Policy (1998).

27 See, e.g., Office of Mgmt. \& Budget, 2012 Report to Congress on the Benefits and Costs of Federal Regulations and Unfunded Mandates on State, Local, and Tribal Entities 54, available at http://www.whitehouse.gov/sites/default/files/omb/inforeg/2012_cb/2012_cost_benefit_ report.pdf. 
significant losses in terms of life and health, and it might also compromise SWB. The financial crisis that began in 2008 was at least plausibly a product of unjustified inaction (including deregulation), and the failure to issue environmental regulations may have serious adverse effects on longevity, health, and SWB. At the same time, it is difficult to assess the magnitude of the problem without a great deal of information, much of which is not publicly available. If the goal is to have a sense of regulatory function and dysfunction, the problem of unjustified inaction deserves considerable attention.

\section{B. Randomized Controlled Trials}

In the past decade, there has been growing interest in the use of randomized controlled trials as a means of learning about the effects of policy initiatives, including regulation. ${ }^{28}$ In medicine, of course, policymakers tend to rely on such trials to see if a drug is safe and effective. The risk with before-and-after assessments is that they may not control for confounding variables. People might be doing better because of some change in the environment that is not adequately understood by those who are making the assessment. In the medical domain, randomized controlled experiments provide a clear sense of the actual effects of the intervention. Esther Duflo, along with several others, has pioneered the use of randomized controlled trials for purposes of policy evaluation. ${ }^{29}$

In the regulatory area, the use of such trials remains in a preliminary state. Analysis of costs and benefits is not usually informed by them. But there have been significant and growing efforts in their direction. Consider, for example, the Behavioural Insights Unit, engaging in a series of randomized trials in the United Kingdom, and corresponding efforts in the United States, whose agencies have made commitments to the use of such trials, and which has seen high-level focus on work in this vein. ${ }^{30}$ It is easy to imagine a wide range of serious evaluations, which would help regulators to obtain a clearer sense of the likely effects on welfare. ${ }^{31}$ For example:

\footnotetext{
28 See generally ABHiJit BANERJEE \& ESTHER Duflo, POOR ECONOMICS (2011).

${ }^{29}$ See id.

${ }^{30}$ For catalogues, see Rhys Jones et al., Changing Behaviours: The Rise of the Psychological State (2013); Cass R. Sunstein, Simpler: The Future of Government (2013). The important work of the Behavioural Insights Team can be found at https://www.gov.uk/government/organisations/behavioural-insights-team. On the United States, see the catalogue of commitments in Sunstein, supra; the important Memorandum to the Heads of Departmenrs, Next Steps in the Evidence and Evaluation Agency (July 26, 2013), http://www.whitehouse.gov/sites/default/files/omb/memoranda/2013/m-13-17.pdf; and the announcement of the U.S. research team working on these issues, Research to Results: Strengthening Federal Capacity for Behavioral Insights (2013), available at http://mail.sjdm.org/pipermail/jdm-society/2013-July/005838.html

31 Michael Greenstone, Toward a Culture of Persistent Regulatory Experimentation and Evaluation, in NEw PERSPECTIVES on REGUlation 113, 113 (David Moss \& John Cisterno eds., 2009); Michael Abramowitz et al., Randomizing Law, 159 U Pa L Rev 929 (2011).
} 
-- Would regulators save lives if they banned the use of cell phones while driving? Laboratory experiments, showing that people's reaction times slow down when they are distracted, strongly suggest that the answer is yes, and indeed that driving while talking on a phone is a bit like driving while drunk, producing a fourfold increase in relative crash risk. ${ }^{32}$ But perhaps those experiments are an unreliable guide to the real world. It would be possible to test whether a ban on cell phone use would have major effects on safety by comparing similarly situated localities, one with such a ban and one without. Or researchers might test whether accidents increase in periods in which cell phone use goes up -- for example, when rates decrease after 9 p.m. ${ }^{33}$

-- What are the effects of different methods of increasing rear visibility in cars? If cameras are placed in the dashboard, do accidents drop? How much, and compared to what? Do improved mirrors have an effect? What about sonar devices, making beeping noises? Do they work as well as cameras? Randomized controlled trials could provide critical information.

-- Disclosure requirements are an important and pervasive regulatory tool, but a great deal remains to be learned about their actual effects; in fact there is a real need to do so. ${ }^{34}$ For example, researchers might test whether different fuel economy labels have different effects on similarly situated consumers. Does one label produce different choices? How different? If labels draw attention to annual fuel costs, are people affected? Do people care about environmental factors? How much? The same kinds of questions might be asked about disclosure requirements for credit cards, mortgages, cell phones, and school loans.

If a randomized trial is not feasible, it might be possible to design experiments that replicate actual behavior by asking people concrete questions about what they would do if provided with certain information or if given a range of options. ${ }^{35}$ But such experiments are second-best. To the extent that the goal is to seek to obtain a clear sense of the welfare effects of regulations, and the existence of dysfunction, randomized controlled trials deserve pride of place.

\section{Ex Ante, Ex Post}

\footnotetext{
32 See Charlotte L. Brace et al., Analysis of the Literature: The USE of Mobile Phones WHILE DRIVING (2007), available at http://www.nsc.org/news_resources/Resources/Documents/Analysis\%20of\%20the\%20Li terature,\%20The\%20Use\%20of\%20Mobile\%20Phones\%20While\%20Driving.pdf.

33 See Saurabh Bhargava \& Vikram Pathania, Driving under the (Cellular) Influence: The Link between Cell Phone Use and Vehicle Crashes 5 Am. Econ. J.: ECON. PolicY (forthcoming 2013), available at www.aeaweb.org/aea/2011 conference/program/retrieve.php?pdfid=182. 34 See George Loewenstein et al., Disclosure: Psychology Changes Everything, Annual Review of Economics (forthcoming 2014).

35 On various possibilities, see Greenstone, supra note.
} 
In producing RIAs, and in seeking to measure the welfare effects of what they plan to do, agencies are of course making ex ante estimates. They attempt to do so on the basis of the best available evidence, but ex ante estimates might turn out to be inaccurate. ${ }^{36}$ Consider this suggestion from Michael Greenstone, former chief economist at the Council of Economic Advisers: "The single greatest problem with the current system is that most regulations are subject to a cost-benefit analysis only in advance of their implementation. This is the point when the least is known and any analysis must rest on many unverifiable and potentially controversial assumptions." 37

This is a plausible objection, and it suggests the immense importance of retrospective analysis, which can help show what actually works and what does not. ${ }^{38}$ Such analysis might in turn promote the repeal or streamlining of ineffective or less effective rules and the strengthening or expansion of those that turn out to do more good than harm. Greenstone urges a series of ambitious reforms designed to promote a culture of experimentation and evaluation. ${ }^{39}$ These reforms include an effort to ensure that regulations are written and implemented so as to facilitate reliable evaluation. President Obama has made a strong commitment to retrospective analysis of rules,,$^{40}$ and the Obama Administration has done a great deal to move in this general direction. But it must be acknowledged that the effort to explore the effects of rules on the books, and to alter them in accordance with what has been learned, remains in a preliminary state. ${ }^{41}$ Further efforts are an indispensable means of reducing the risk of regulatory dysfunction.

\section{Conclusion}

Well-functioning institutions increase the probability that citizens are able to live good lives. In many domains, they do so by creating competitive markets and allowing them to do their own. In other domains, they do so by solving collective actions problems and by responding to market failures of various sorts (including behavioral market failures). The analysis of dysfunction should focus on the concrete consequences of regulatory action for people's lives.

\footnotetext{
36 On the current record, which shows no systemic bias but a significant number of mistaken predictions, see Sunstein, supra note.

37 Michael Greenstone, Toward a Culture of Persistent Regulatory Experimentation and Evaluation, in NEw PERSPECTIVES on REgUlation 113, 113 (David Moss \& John Cisterno eds., 2009).

38 See Randall Lutter, Regulatory Policy: What Role for Retrospective Analysis and Review, 4 J. of Benefit-Cost Analysis 17 (2013).

39 Id.

40 See Exec. Order No. 13,563 § 1, 3 C.F.R. 215, 215-16 (2012), reprinted in 5 U.S.C. $§ 601$ app. at 101-02 (2006 \& Supp. V 2011); Sunstein, Simpler, supra note.

41 See id.
} 
That focus leaves many questions unresolved, but it should be possible to achieve an incompletely theorized agreement on a kind of nonsectarian welfarism, emphasizing the importance of five factors: subjective well-being, longevity, health, educational attainment, and per capita income. In principle, it would be valuable to identify the effects of new initiatives, including regulations, on these factors. In practice, it is not feasible to do. In their ideal form, Regulatory Impact Statements should be seen as Nonsectarian Welfare Statements, seeking to specify the consequences of regulatory initiatives for various components of welfare. So understood, they provide reasonable measure of regulatory success or failure, and hence a plausible test of dysfunction. But ex ante estimates may well be unreliable, especially to the extent that they are based on guesswork and extrapolation. There is a pressing need for improved evaluations, including randomized controlled trials and ex post assessments. 